\title{
VISÃO DOCENTE FACE O USO DE TICS E METODOLOGIAS ATIVAS NO CENÁRIO DE PANDEMIA
}

\begin{abstract}
Teacher's view on the use of ICTs and active methodologies in the pandemic scenario
\end{abstract}
\author{
Francicleia Gomes Camilo ${ }^{1}$ \\ Thamy Saraiva Alves ${ }^{2}$ \\ Mílvio da Silva Ribeiro ${ }^{3}$
}

RESUMO: O presente artigo analisa a experiência de uso de metodologias ativas aliadas às TICs no ensino superior, aplicados através do ensino remoto em tempos de Pandemia no âmbito do COVID-ı no município de Redenção-PA. A reflexão é feita sobre a experiência docente e discente na utilização de metodologias ativas no ensino remoto e adequação vivenciada no ensino superior presencial em período de Pandemia para a turma de Direito na IES privada em RedençãoPA. Do ponto de vista metodológico, realizou-se levantamento bibliográfico sobre tipos de TICs e metodologias ativas. Construiu-se um plano de aula remota instrumentalizado pela metodologia ativa. Percebeu-se nos educadores a reinvenção e buscas de estímulos a aprendizagem, de modo que a inserção de metodologias ativas é instrumento que desperta a participação, proporciona uma prática construtivista da aprendizagem, gera interesse, comprometimento e humildade nas trocas de saberes.

Palavras-chave: Metodologias ativas. Pandemia. Formação continuada. Inovação.

ABSTRACT: This article analyzes the experiencie of using active methodologies combined with ICTs in higher education, applied through remote education in times of Pandemic within the scope of COVID-19 in the municipality of Redenção-PA. The reflection is made on the teaching and student experiencie in the use of active methodologies in remote education and adequacy experienced in on-campus higher education in a period of Pandemic for the Law class at the private HEI in Redenção-PA. From a methodological point of view, a bibliographic survey was conducted on types of ICTs and active methodologies. A remote lesson plan was built using the active methodology. It was perceived in educators the reinvention and search for stimuli to learning, so that the insertion of active methodologies is an instrument that arouses participation, provides a constructivist practice of learning, generates interest, commitment and humility in the exchange of knowledge.

\footnotetext{
I Faculdade de Ensino Superior da Amazônia Reunida, FESAR, Redenção-PA, Brasil. E-mail: fgcamilo.dv@gmail.com.

${ }^{2}$ Universidade do Estado do Pará, (UEPA), Belém-PA, Brasil. E-mail: thamysalves@yahoo.com.br

3 Universidade Federal do Pará (UFPA); Faculdade de Teologia, Filosofia e Ciências Humanas Gamaliel (FATEFIG), Tucurui, PA, Brasil. E-mail:milvio.geo@gmail.com.
} 
Keywords: Active methodologies. Pandemic. Continuing education. Innovation.

\section{INTRODUÇÃO}

No cenário atual o mundo enfrenta um impasse na adequação ao modo de desenvolver uma aprendizagem significativa. Pensar as formas de interagir com o discente de forma remota ou a distância tornou-se pauta de lives, workshops e discussões no meio virtual. A Educação superior vem buscando formas eficazes para manter o aluno consciente da importância de continuar o estudo, mesmo em tempo de pandemia, pois, vários são os empecilhos que vêm causar uma certa insegurança aos grupos gestores e professores das IES. Todo o Brasil foi pego de surpresa, docentes e discentes saíram de suas zonas de conforto, foram obrigados a adaptarem-se às novas formas de ensinar e aprender, aliadas aos ambientes virtuais. As IES de todo o Brasil passam, então, a obedecer às portarias emitidas pelo Governo Federal.

Conforme Brasil (2020a), no âmbito do Ministério da Educação (MEC), através da Portaria $\mathrm{n}^{-}$343, de 17 de março de 2020, art. Iํㅡ, autorizou-se - em caráter excepcional - a substituição das disciplinas presenciais, em andamento, por aulas que utilizem meios e tecnologias de informação e comunicação, nos limites estabelecidos pela legislação em vigor, por instituição de educação361 superior integrante do Sistema Federal de Ensino, de que trata o art. $2^{\circ}$ do Decreto no 9.235 , de 15 de dezembro de 2017 (BRASIL, 2017). Em primeiro momento, todo o Brasil entrou em choque, devido à urgência de mudanças repentinas na modalidade de ensino.

Brasil (2020b), através da Portaria 345 de 19 de março de 2020, no $\$ 3^{\circ}$ foi vedada aplicação a aplicação da substituição das atividades de estágios e laboratórios por aulas remotas; já especificamente para o curso de Medicina, no $\S 4^{-}$autorizou a substituição para apenas as disciplinas teóricas do primeiro ao quarto ano do curso e que as IES deverão informar ao MEC sua opção por substituir as aulas por remotas no período de até is dias.

Em Brasil (2020c), por meio da Portaria no 395, de is de abril de 2020 foi prorrogado o prazo

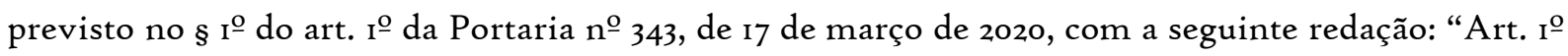
vem prorrogar, por mais trinta dias, o prazo previsto no § I을 do art. I o da Portaria no 343 , de 17 de março de 2020". As deliberações de prorrogação de datas foram emitidas no intuito de amparar as IES a continuarem com equilíbrio e pensando em garantir a segurança de todos.

A portaria 343, de 17 de março de 2020, vem estender o prazo de substituição de atividades presenciais educacionais por mais trinta dias, trazendo ainda algumas restrições, logo esta portaria é alterada pela portaria 345/2020: 


\begin{abstract}
Art. Io Fica autorizada, em caráter excepcional, a substituição das disciplinas presenciais, em andamento, por aulas que utilizem meios e tecnologias de informação e comunicação, por instituição de educação superior integrante do sistema federal de ensino, de que trata o art. $2^{-}$do Decreto $\mathrm{n}^{\circ}$ 9.235, de 15 de dezembro de 2017.
\end{abstract}

PORTARIA № 473, DE 12 DE MAIO DE 2020: Prorroga o prazo previsto no § I ${ }^{\mathrm{o}}$ do art. Io da Portaria no 343 , de 17 de março de 2020. Art. Io Fica prorrogado, por mais trinta dias, o prazo previsto no $\S \mathrm{I}^{\mathrm{o}}$ do $\operatorname{art}$. $\mathrm{I}^{\mathrm{o}}$ da Portaria $\mathrm{n}^{\mathrm{o}} 343$, de 17 de março de 2020 .

PORTARIA № 544, DE I6 DE JUNHO DE 2020: Dispõe sobre a substituição das aulas presenciais por aulas em meios digitais, enquanto durar a situação de pandemia do novo coronavírus - Covid-ı, e revoga as Portarias MEC no 343 , de I7 de março de 2020, no 345, de 19 de março de 2020, e no 473 , de 12 de maio de 2020.

O Governo Federal através do Ministério da Educação, a título de organização, vem criteriosamente emitindo estes documentos que deliberam sobre a troca de meios e ferramentas. As instituições promoveram os planos de contingência seguindo as portarias. Em Brasil (2020d), a Portaria 544/2020 estabeleceu que o período de aulas por meios digitais para a substituição de aulas presenciais se estenderá até dia 3I de dezembro de 2020. Deixando claro e evidente que as IES poderão continuar com as aulas por meios tecnológicos até dezembro de 2020 , as instituições 362 poderão alterar o calendário de férias, desde que cumpra a carga horária dos cursos conforme a legislação em vigor. Através deste documento ficam revogadas as portarias anteriores, a 343 de 17 de março, 345 de 19/03, a 473 de 12 de maio de 2020.

O objetivo desta pesquisa é refletir sobre a visão dos docentes e discentes sobre a experiência acerca do uso das tecnologias digitais e novas ferramentas no ensino considerado "remoto". Este estudo se justifica por se tratar de conhecimentos novos, mediante cenário de isolamento social. E, assim, refletir a problemática na tentativa de compreender a visão docente sobre as dimensões do acesso ao ensino e às condições oferecidas pelas IES.

Para identificar a aplicabilidade de novas formas de ensinar e aprender, desenvolveu-se o estudo bibliográfico com base em autores que versam sobre a temática da pesquisa, com metodologia de cunho qualitativo, buscando suas impressões referentes à ação do semestre 2020.I diante do cenário de isolamento social, onde os alunos já não estão próximos. Para análise, far-se-á a exposição de um dos planos criados pelos docentes. Ambos se disponibilizaram a contribuir com seus depoimentos, via questionários do Google Forms, com perguntas de cunho subjetivas e, por solicitação de ambos, suas identidades não serão expostas. Pressupõe-se que os relatos de vivência pretendem investigar sobre as diversas possibilidades de uso das tecnologias e metodologias; instigar a reflexão sobre o papel docente neste contexto denominado ensino remoto; desenvolver a 
percepção docente para aprofundar seu conhecimento sobre o uso de TICs e metodologias, incorporando em seu universo de prática para que sejam utilizadas como trampolim para o ensino e aprendizagem no ensino superior.

Esta discussão não é nova, porém a reflexão acerca do uso das tecnologias e novos métodos de ensino poderá contribuir para trazer a reflexão sobre as novas formas de ensinar e aprender. Para tanto, destaca-se as metodologias ativas, assim como apresenta-se um breve conceito sobre ABP (Aprendizagem baseada em projetos) como ferramenta auxiliar. E nas considerações finais, além de relatar a ampla análise do estudo, deixamos reflexões para futuras pesquisas, a respeito da situação da COVID-ı́ no âmbito educacional e cultural.

\section{Referencial Teórico}

Concluída a revisão da literatura, foi utilizada uma abordagem qualitativa, ou seja, não expressa por números, mas envolvendo descrições, impressões e compreensões, análises e reflexões de informações (MARTINS; THEÓPHILO, 2007).

A abordagem teórica da pesquisa que norteia o desenvolvimento desta investigação está fundamentada no uso das TICs e metodologias ativas de ensino como possibilidade de (re)significação da prática docente. Para tanto, inicialmente, faz-se uma apresentação minuciosa do que se entende por Tecnologias da Informação e Comunicações e metodologias ativas de ensino, conceituando as características atreladas a elas. Esta caracterização irá direcionar os estudos posteriores, permitindo articulação em outras abordagens, entre as demais metodologias ativas para esta temática priorizou-se a aplicação da aprendizagem baseada em projetos (ABPROJ), haja vista que este método se encaixa no planejamento prático, apresentado pelos docentes pesquisados.

\section{TICs e Metodologias Ativas e Aprendizagem Significativa, a recíproca entre o docente e discente}

É importante frisar que a educação superior vem metamorfoseando sua pedagogia ao ensinar; prioriza uma educação inovadora embasando em propostas condutoras. Porém, o "novo" ainda traz estranheza. Para Bauman (2003), oportunidades variadas com tempo previsto, líquidas e fluidas dão suporte pela movimentação e experiência humana.

Há uma janela de oportunidades para as instituições manterem o uso de recursos digitais nas suas aulas, mas de uma maneira planejada. Vejo duas situações. Em primeiro lugar, aquelas que estão fazendo um bom trabalho na migração - muitas vezes porque já tinham cursos à distância - geram um potencial para os alunos entenderem as vantagens a ponto de migrarem para o EAD no futuro $(\mathrm{BACICH}$, 2020). 
O novo é uma das condições que funciona como chave propulsora, motivadora e lúdica. As instituições voltadas para diversos ramos têm a convicção de que os novos métodos trazem benefícios. Em razão disto, buscam por ferramentas inovadoras como as TICs e as metodologias ativas; para incentivar o crescimento, investem em recursos financeiros, regulamentação econômica e outras bases que venham fortalecer as demandas. $O$ principal mediador deste processo é o capital humano que deve ter conhecimento de causa para, ou seja, desenvolver a formação e a aprendizagem para as novas formas "inovar". As metodologias ativas são atividades interativas elaboradas pelo professor com o objetivo de encontrar soluções para problemas, casos, projetos.

Incorporar as novas formas de ensino e aprendizagem, aplicar as tecnologias de comunicação e informação para adaptação de novas gerações, é de extrema necessidade para o momento atual, para facilitar a inclusão digital. A evolução tecnológica e o advento de novas ferramentas propiciaram novas formas de propagação de informações (KENSEY, 2015).

A linguagem digital, expressa em múltiplas TICs, impõe mudanças radicais nas formas de acesso à informação, à cultura e ao entretenimento. $O$ poder da linguagem digital, baseado no acesso a computadores e todos os seus periféricos, à internet, aos jogos eletrônicos etc., com todas as possibilidades e convergência e364 sinergia entre as mais variadas aplicações dessas mídias, influencia cada vez mais a constituição de conhecimento, valores e atitudes; cria uma nova cultura e uma nova realidade informacional (KENSEY, 2015, p. 33).

As trocas de informações entre os aprendizes, docentes e IES, a internet é um dos principais meios neste processo de mudanças na maneira em que ocorrem estas trocas. $\mathrm{Na}$ utilização das tecnologias de informação e comunicações (TICs) no processo de ensino aprendizagem por meio da comunicação, a sua eficácia deve ser observada tornando-a mais atrativa e dinâmica para os seus receptores (MORAN, 2015). Para que a comunicação atenda os objetivos propostos dentro do âmbito educacional, os recursos utilizados devem atender aos critérios de aplicação.

Incorporar as TICs ao processo de ensinar e aprender requer a utilização de recursos apropriados, visto que as tecnologias de informação podem ser compreendidas como '[...] o conjunto de técnicas, processos, métodos, meios e instrumentos [...]' utilizados pelos indivíduos ao comunicar-se. Para planejar o processo de ensino aprendizagem com a utilização das TICs faz-se necessário centrar o planejamento das atividades levando em consideração a utilização destas ferramentas na consulta à base de dados e informações, na comunicação, na interação e na construção de conteúdo (CARVALHO; IVANOFF, 2010, p. 4).

O processo educativo é mais do que simples teoria, é proporcionar aos alunos a oportunidade de reinventar, transformar suas vidas e obterem aprendizado mais prazeroso. Consequentemente haverá aí uma recíproca entre docente e discentes. Segundo Moran (2007), é 
ajudar os alunos a construir sua real identidade, garantindo a execução de seu projeto de vida, é subsidiar o desenvolvimento de habilidades e competências para que se tornem produtivos.

As Metodologias Ativas (MAs) têm uma concepção de educação crítico-reflexiva com base em estímulo no processo ensino-aprendizagem, resultando em envolvimento por parte do educando na busca pelo conhecimento. Dentro do conceito de metodologia ativa, existe o método a partir da construção de uma situação problema (SP), ${ }^{4}$ a qual proporciona uma reflexão crítica; mobiliza o educando para buscar o conhecimento, a fim de solucionar a SP; ajuda na reflexão e a proposição de soluções mais adequadas e corretas. As concepções teóricas e metodológicas da $\mathrm{MA}^{5}$ convergem com a Metodologia da Problematização (MP). ${ }^{6}$

Segundo Barbosa e Moura (2013), metodologias ativas, às vezes, podem parecer estranheza para determinados professores que atuam no campo da $\mathrm{EPT}^{7}$. De forma natural em seu cotidiano, o professor já vem aplicando novas formas de ensino, como exemplo temos o desenvolvimento de projetos que na grande maioria partem da concepção de um problema. $O$ ensino por meio de projetos, assim como o ensino por meio da solução de problemas são exemplos típicos de Metodologias Ativas de Aprendizagem.

Berbel (20II) afirma que as metodologias ativas propiciam a aprendizagem por meio de 365 práticas realizadas nas disciplinas estudadas. Estes meios aliados à área de informática facilitando a resolução de questões, estudo de casos, iniciação científica, elaboração de resenhas, artigos científicos e realização de projetos e outros meios. Com o uso dos métodos ativos, o professor atua como mediador do processo, orientando e despertando no aluno a reflexão sobre os conteúdos estudados. Assim, se tornando um sujeito autônomo para a tomada de decisões (OLIVEIRA, 2013). Para Bessant e Tidd (2009, p. 20), "se não nos atualizarmos para prestar nossos serviços e como os moldamos e ofertamos, corremos um grande risco de sermos substituídos por outros que estão preparados".

O profissional docente deve estar preparado para atuar profissionalmente. Dele é exigido a aquisição de habilidades e competências de variados modos para gestão nas disciplinas e a elaboração e execução de planos resilientes às situações. É perceptível que sua trajetória sempre almejará por planos $\mathrm{A}, \mathrm{B}$ e $\mathrm{C}$ para o enfrentamento de desafios que surgem conforme as situações.

\footnotetext{
4 SP: Solução de problema.

${ }^{5}$ MA: Metodologia ativa.

${ }^{6}$ MP: Metodologia de problematização.

7 EPT: Educação Profissional Tecnológica.
} 
É preciso que um novo profissional docente conhecedor profundo das interrelações pedagógicas, políticas e tecnológicas nas atividades de ensino e aprendizagem esteja presente para dimensionar, programar e orientar com habilidade a produção de ações educativas, que vá ao encontro das necessidades de formação continuada das pessoas em diferenciados caminhos (KENSKI, 2013, p. 20).

De acordo com Souza et al. (2014), os currículos inovadores buscam priorizar os métodos ativos de aprendizado, definindo a aprendizagem baseados em resultados e competências e enfatizando aquisição de habilidades e atitudes bem como do conhecimento. Esta demanda ascende fortemente à busca por métodos inovadores, os quais exerçam uma prática reflexiva, crítica, transformadora e emancipadora, que vá além do modelo de educação bancária praticado até então. Para tanto, é possível definir a metodologia ativa como uma ferramenta propulsora para a aprendizagem significativa:

As metodologias ativas são atividades interativas elaboradas pelo professor com o objetivo de encontrar soluções para problemas, casos, projetos. Atuando como mediador e orientador do processo, o professor instiga o aluno a refletir e tomar suas próprias decisões sendo o principal responsável por seu próprio aprendizado (OLIVEIRA, 2013, p. 9).

A utilização de metodologias ativas no processo de ensino aprendizagem desperta a 366 curiosidade dos alunos. Isso faz com que o aluno se ocupe em fazer algo e ao mesmo tempo reflita sobre a atividade que está executando.

Fazer o "Novo", inovar se aplica em uma diversidade de âmbitos, áreas, produtos e serviços, não é diferente na educação, onde as propostas estão em crescente mudança no que tange o ensino e aprendizagem.

Está, porém, ainda por se provar que o ato de aprender se realiza mais adequadamente quando é transformado em uma ocupação especial e distinta. A aquisição isolada do saber intelectual, tentando muitas vezes a impedir o sentido social que só a participação em uma atividade de interesse comum pode dar, deixa de ser educativa, contradizendo o seu próprio fim. $O$ que é aprendido, sendo aprendido fora do lugar real que tem na vida, perde com isso o seu sentido e o seu valor (DEWEY, 1978, p. 27).

As metodologias Ativas são sistematizadas, pois, para sua efetividade, é necessário que o professor mediador pense e planeje para que haja o interesse do estudo e haja a recíproca em relação ao interesse do estudante.

A aprendizagem significativa pode ser considerada como um processo de organização de informações e sempre que possível deve ser apoiada nos conhecimentos que o estudante traz consigo. Blikstein (2010) afirma que o envolvimento dos alunos com a M.As. garantem que os 
alunos ao saírem da universidade, saiam com experiencias nas áreas etudadas, deixando a ilusão de ter aprendido devido à exposição de conteúdos em aulas tradicionais.

É importante frisar que a interação com o meio promove a aprendizagem significativa. As novas metodologias são diversas: peer instruction (pi), just-in-time, teaching (jitt), aprendizagem baseada em times (tbl), métodos de caso, mapas conceituais, design thinking, sala de aula invertida e, por fim, a aprendizagem baseada em problemas e aprendizagem baseada em projetos (pbl), essas novas ferramentas devem ser aplicadas a cada componente de forma que proporcione o engajamento dos alunos.

\section{Aprendizagem Baseada em Projetos (ABPROJ)}

Neste estudo tratou-se especificamente da sincronia das aulas, alunos, professores nos ambientes virtuais na condição atual (COVID-19). Em contrapartida, traz-se a definição da metodologia ativa denominada ABP, utilizada no plano docente, adaptado na disciplina Projeto Dirigido de Aprendizagem do curso de Direito de uma faculdade em Redenção-PA.

Portanto, a Metodologia Ativa ABP enfatiza as atividades que levem à elaboração de367 projetos, cuja principal característica é a construção coletiva do conhecimento interdisciplinar e centrada no aluno. Sua ação fundamenta-se na utilização de temas transversais e interdisciplinares, possibilitando ao aprendiz uma visão geral do conhecimento (MARKHAM; LARMER; RAVITZ, 2008).

É possível denominar projetos como objetos definidos que nascem a partir de uma problemática que envolva uma comunidade e seus interesses e de demais pessoas, ou até mesmo organizações com o objetivo de oportunizar uma contribuição que venha suprir determinadas oportunidades. A ideia de que o homem é perfeitamente capaz de aprender através de resolução de problemas aflora a partir do século XIX, embasada por autores que tiveram a preocupação em fomentar tal pedagogia, como por exemplo, John Dewey em 1897 (BARBOSA; MOURA, 2013, p. 6I). Os projetos, na prática, seguem diretrizes para as efetividade e alcance de objetivos:

- delimitação de temas com objetivos didáticos e prioridades em consonância com professor orientador;

- trabalhos em coletividade (4 a 6 alunos);

- objetivo concreto, claro para a percepção da importância dos projetos;

- tempo estimado para desenvolvimento e finalização (02 a 04 meses);

- a utilização de várias ferramentas para o desenvolver da pesquisa (projeto);

- feedback (com a escola, comunidade e sala de aula) de processo de estudo, pesquisa, resultados em todas as fases. 
É importante observar as principais fases de como se dá tal método na prática, suscitando uma melhor interação entre os envolvidos, de forma que haja um aperfeiçoamento ao resolver problemas escolhidos com muita sensibilidade, desde o mais simples aos mais complexos. De acordo com Barbosa e Moura (2013, p. 63), há três categorias deste método:

(a) Projeto construtivo: visa construir algo novo, introduzindo alguma inovação, propor uma solução nova para um problema ou situação; possui a dimensão da inventividade, na função, na forma ou no processo;

(b) Projeto investigativo: desenvolvimento de pesquisa sobre uma questão ou situação, mediante o emprego do método científico;

(c) Projeto didático (ou explicativo): procura responder questões do tipo: "como funciona? Para que serve? Como foi construído?" Busca explicar, ilustrar, revelar os princípios científicos de funcionamento de objetos, mecanismos, sistemas etc. As metodologias ABProb e ABProj, sejam comuns e favoráveis ao ensino aprendizagem no Ensino superior, ambas são diferentes.

A tabela I apresenta algumas variáveis entre as duas formas de instigar a autonomia discente.

Tabela I - Variáveis entre ABProb e ABProj

\begin{tabular}{|c|c|}
\hline ABProb & ABProj \\
\hline Origem em problemas & Caso, situação geradora \\
\hline $\begin{array}{l}\text { Problemas definidos pelo professor em } \\
\text { consonância com os conteúdos e curso. }\end{array}$ & $\begin{array}{l}\text { Problemas definidos pelos alunos orientados } \\
\text { pelo professor para uma melhor motivação por } \\
\text { parte de ambos. }\end{array}$ \\
\hline Duração de curto prazo (2 a 4 meses) & Duração- 04 a 12 semanas \\
\hline Etapas definidas & Processo com etapas abertas \\
\hline Análise e solução de problema & O nascer de algo inovador \\
\hline Produto não-obrigatório & Obrigatório um produto \\
\hline $\begin{array}{l}\text { Em comum } \\
\text { Esse método de ensino requer motivação, ha } \\
\text { discente. Favorece uma aprendizagem significati } \\
\text { a criatividade e inovação, promove a formação }\end{array}$ & $\begin{array}{l}\text { ilidades específicas, dedicação do professor e } \\
\text { a, contextualizada e interdisciplinar, motivando } \\
\text { efetiva para o mundo do trabalho, tornando o }\end{array}$ \\
\hline
\end{tabular}

Fonte: Adaptação realizada por Barbosa e Moura (2013 p. 64).

É possível combinar sala de aula com ambientes virtuais. Segundo Moran (2015), este processo é de grande relevância, aliando as TICs e métodos novos de ensinar para derrubar os muros da escola e abrir as portas para a comunidade e propiciar a recíproca neste ato. Neste contexto, o docente fica encarregado de sistematizar o processo de ensino aprendizagem com democracia e motivação, voltado para o aprendiz. 


\section{Demonstração de projeto de trabalho}

Em março de 2020, a educação brasileira entra com o plano de contingência buscando garantir o cumprimento dos planos de ensino. Professores e alunos mudam repentinamente de cenário de ensino/aprendizagem, os planos de aulas são adaptados para ferramentas virtuais tais como Zoom, Meet e Google Classroom. Tais fatores são objetivos de discussões nas redes sociais, onde diversos profissionais buscam amenizar o choque de mudança de cenário, pois, vários problemas surgem face à nova situação, porque o processo de ensino envolve os aspectos emocionais, cognitivos e sociais.

Ao elaborar o plano de trabalho, o docente busca promover e acompanhar o processo do desenvolvimento de projetos propostos, antes de forma presencial, onde o professor mediador orienta a cada fase, com retornos pontuais, feedbacks e orientações, agora o planejamento e a forma de mediar passam por novos métodos. Os acadêmicos receberam as orientações sobre a proposição dos projetos, suas etapas e que estes seriam realizados de forma coletiva, da mesma maneira a escolha do tema. A atividade expressou o objetivo de proposta do projeto por meio de orientações claras e de critérios de avaliação para nortearem o processo de ação e as discussões para elucidar as dúvidas metodológicas e como ocorreram as ações anteriores de forma presencial.

No período de março de 2020 - quando iniciou a pandemia -, os alunos já estavam de posse do processo de elaboração do planejamento da pesquisa, partem para os ajustes através de feedbacks e orientações via Zoom. A denominação correta é aula síncrona, onde todos estão em perfeita sincronia durante o período estipulado (MARTINS et al., 2020). Inicialmente, docentes e discentes enfrentaram uma certa estranheza para lidar com o tempo, a compreensão e a motivação. O professor apresentou a proposta a seguir:

Tabela 2 - Demonstração de projeto de trabalho em tempo de Covid- 19 - março 2020

- Após a descrição da proposta da atividade, o professor e discentes atuaram no desenvolvimento do projeto, a partir da seleção de bibliografias e de exemplos, orientações pontuais e flexibilização de datas para finalização do trabalho proposto. Ambos passaram pelo processo de etapas (pré-projeto e trabalho final com os dados coletados e resultados obtidos), onde a prioridade era desenvolver os critérios metodológicos da pesquisa científica com base na temática escolhida por cada grupo.

- O docente desenvolveu ainda o papel impulsionador e motivador, buscando incentivar os alunos a interagirem em grupo de forma virtual e por meio de mídias sociais, onde os relacionamentos se estreitaram de uma certa forma devido à situação de pandemia; é importante ratificar sobre o uso das mídias e de AVAS que requer acesso à internet, um dos fatores 
denominados empecilhos.

- Discutir a elaboração do projeto do grupo. Desenvolver a apresentação do projeto para ser postado na ferramenta base de dados até o prazo final da atividade. Escolher um responsável pela postagem do Projeto final (no formato escolhido pelo grupo).

- Ao finalizarem as etapas de orientações, o docente realizou as avaliações dos trabalhos, segundo os critérios apresentados para a turma inicialmente. Importante destacar que o foco do desenvolvimento do trabalho foi priorizar a participação dos alunos. Para tanto, os principais aspectos foram: a comunicação, colaboração e cooperação de todos os componentes dos grupos, e o produto final.

Esta atividade buscou garantir o plano proposto, com objetivo de superar os desafios com o auxílio de diversas ferramentas advindas de ambientes virtuais, com o propósito de engajar os alunos e torná-los colaboradores e produtores de conhecimentos.

A proposta desta atividade buscou sanar estes desafios através do uso de diferentes ferramentas disponíveis no ambiente virtual, que serviram para engajar a colaboração dos alunos. Para este momento conturbado, onde os desafios são muitos, utilizou-se as ferramentas denominadas Zoom, Google Calssroom e WatzApp e plataforma Sistema Faculdade.

Escolha de ferramentas: Google Classroom e Zoom, inicialmente utilizados para que os alunos se organizassem em grupos e trabalhassem colaborativamente na discussão do projeto.

Tirar dúvidas do processo: as dúvidas sobre a elaboração da atividade e demais questões puderam ser sanadas via zoom, WhatsApp.

Sugestões de página Web e Google Classroom: onde foram disponibilizados alguns exemplos de projetos disponíveis online, e Base de Dados.

No sistema faculdade: onde as aulas e atividades foram registradas e ambiente para os alunos 370 postarem as atividades para correção.

Seminários on-line: que os grupos compartilhassem a versão final do Projeto com os demais participantes do curso e recebessem os comentários gerais.

Os seminários online para que os grupos compartilhassem a versão final do Projeto com os demais participantes do curso e recebessem os comentários gerais.

Fonte: Camilo (2020).

O professor atuou como agente motivador e em tempo de Covid-I9 este processo motivacional se torna ainda mais necessário para impulsionar os discentes a buscarem soluções para as questões denominadas problemas, levando-os à elaboração dos projetos. Este processo foi mediado a partir de discussões, onde o docente trouxe alguns modelos prévios selecionados para melhor entendimento dos aprendizes. As orientações foram realizadas no Zoom, ora no WhatsApp, cujos links foram disponibilizados para melhor credibilidade dos alunos ao desenvolverem as pesquisas.

Todas as orientações foram possíveis através do acesso tanto no aparelho celular como no computador, o docente buscou apresentar a proposta de atividades e os devidos critérios avaliativos do processo de aprendizagem discente om clareza e objetividade, facilitando a participação ativa de todos os envolvido nos projetos.

Para o suporte e orientação dos grupos durante o processo de construção do projeto, docentes e os alunos subsidiaram discussões sobre a temática, demonstrando disposição para a 
colaboração e construção do projeto. As interações registradas possibilitaram ao professor mediador a oportunidade de acompanhar o processo de estudos e desenvolvimento do projeto de cada grupo.

Foram apresentados 7 grupos de trabalhos desenvolvidos com a participação ativa de 30 (trinta alunos). Ao finalizarem, os grupos apresentaram:

Gı: Tema - Habitação e infraestrutura: os parâmetros das moradias populares de XinguaraPA;

G2: Levantamento de dados socioeconômicos no município de Redenção-PA: segurança na comunidade redencense;

G3: Levantamento de dados socioeconômicos no município de Redenção-PA: transporte, mobilidade e acessibilidade;

G4: Aplicabilidade do direito no âmbito da agricultura.

G5: Mapeamento de dados do perfil socioeconômico de Redenção-PA: educação;

G6: O saneamento básico como ferramenta essencial ao desenvolvimento e sustentabilidade socioeconômica no município de Redenção-PA;

G7: Programas, projetos e ações em desenvolvimento no município de Redenção - PA.

Os grupos de trabalho com suas peculiaridades e habilidades executaram o plano com enfrentamento à situação, buscando atender aos objetivos de seus respectivos temas. A aprendizagem individual é peculiar, adequável à situação para a aquisição de habilidades e competências intrínsecas a cada um. Neste cenário, este estudo atenta para a compreensão do olhar 371 dos sujeitos pesquisados. Desse modo, apresentamos em relatos e discussões, com fins de apresentar ao leitor suas impressões e consequentemente uma possível sugestão quanto a este processo de ensino aprendizagem, usando como base a aprendizagem baseada em projetos.

\section{Discussão}

Antes do cenário epidemiológico, no Brasil, tornar-se sujeito do processo de aprendizagem já era considerado uma realidade no universo do ensino superior, pois, a grande maioria das universidades brasileiras já vinham implantando esta mentalidade do emprego de novas metodologias. Construir coletivamente é fundamental para a aquisição da aprendizagem baseada em projetos $(\mathrm{ABP})$, onde é desafiante promover o envolvimento para a realização das tarefas propostas - haja vista que esta metodologia ativa é de fácil monitoramento e mediação docente. Assim, o papel do professor mediador no acompanhamento das ações durante a construção do projeto permite sua atuação na mediação e resolução de conflitos.

A utilização de novas formas de ensinar neste período de isolamento traz uma eficácia com a diversidade de ferramentas. Sua utilização favoreceu o trabalho do professor no acompanhamento, orientações e feedbacks e fortaleceu e tornou possível o trabalho colaborativo, propiciando a reflexão dos alunos acerca de suas práticas como principal sujeito do processo. 
Para a reflexão desta temática foi realizada a análise de relatos de experiências vividas por professores e alunos como atores. O docente mediador - relator I demonstra como foram elaboradas as atividades nas metodologias ativas; o docente - relator 2 relata sobre acompanhamento e feedbacks; e finalmente os discentes como relatores 3 e 4 como participantes do processo de elaboração do planejamento de pesquisa (projeto) conforme tabela abaixo:

Tabela 3. Relatos de experiências vividas por professores e alunos como principais agentes do processo de ensino em tempo de Covid-ı

Docente - relator I: atuei como mediadora, orientadora e avaliadora, para tanto é importante afirmar categoricamente que a formação pedagógica ofertada pela faculdade trouxe uma certa segurança no cenário atual, necessariamente tive que adaptar os planos elaborados para o ensino presencial para o remoto e com urgência. Trabalhar com projetos requer planejamento e criação de bons problemas que instiguem os alunos a pensarem, pesquisarem e agora mais do que nunca com autonomia, uma vez que o momento requer mais engajamento e dedicação. É importante ressaltar que desenvolver projetos foi desafiador, porque os alunos em março de 2020 já haviam escolhido seus temas e já socializavam de forma presencial em grupo, com pretensões de realizar as pesquisas in loco. Quando a pandemia chegou, foi urgente a discussão do método a ser aplicado na elaboração e execução dos projetos, no entanto as atividades foram idealizadas, planejadas com base nas metodologias ativas, em particular, a ABP. A partir daí concentramos a atenção em nos comunicarmos através da plataforma Zoom. Inicialmente tivemos que aprender a operar esta ferramenta que chegou para efetiva contribuição, e para a adição das elaborações de cada grupo utilizamos Google sala, TICs que auxiliaram na comunicação nos relacionamentos, nas dúvidas. O Google sala nos proporcionou a flexibilização de prazos, verificar como avaliar, se o aluno estava como coadjuvante, participando e desenvolvendo as atividades, literalmente favorecendo o acompanhamento, as discussões. Inicialmente, foi difícil para todos, estamos nos adaptando, teremos que lidar com o isolamento social, com a dúvida sobre a postura do aluno do outro lado e com a consciência de que devemos buscar renovar nossos conhecimentos sobre as TICs e métodos ativos.

Docente - relator 2: para facilitar a comunicação em tempo de isolamento social e trazer os alunos para junto, para a sala de aula remota, estabelecemos uma comunicação por meio dos fóruns de discussão, e-mail interno, chats, WhatsApp e demais ferramentas que favorecem a interação aluno-professor. Realizei o acompanhamento das atividades seguindo a ordem de datas, mas também flexibilizando quando necessário. Incentivei, elogiei a todos pela superação dos desafios que não se concentravam somente nas ferramentas interacionais utilizadas, mas também o isolamento, acesso a net, fatores esses que em alguns momentos impossibilitaram ao aluno de participar das aulas e orientações. Me senti na responsabilidade de me comunicar até fora do horário de aulas, buscando manter a regularidade do aluno nas aulas remotas, para então mediar e avaliar as atividades propostas. É importante ainda verificar a questão de acessibilidade aos novos métodos por questões de localização e outras dificuldades apresentadas pelos alunos dentro dos aspectos psicossociais.

Discente - relator 3: iniciamos as atividades em grupo, já havíamos tematizado nossos projetos e partiríamos para a elaboração, as atividades propostas nos deixaram com vontade de indagar, conhecer sobre cada tema. Logo, surge novo cenário que nos pegou de surpresa, mas a IES estava preparada, em nenhum momento percebemos momentos de instabilidade nos métodos; os professores com certeza duplicaram suas cargas de trabalho fazendo adaptações para continuarmos em frente, mudamos a forma da pesquisa para sites e fontes bibliográficas. No início ficamos perdidos, mas, nas aulas remotas, fomos nos adaptando e entramos no ritmo; aula orientação, correção, discussão e feedbacks foram cruciais para que pudéssemos finalizar as etapas propostas. Todos os professores foram motivadores, nos incentivaram a buscar informações nas redes (web) 
sobre as problemáticas de nossos projetos. A utilização das tecnologias foi muito importante para nos apoiar, enfrentar todas as tarefas que foram propostas e ainda nos fortaleceu para interagirmos em grupo. Meu grupo elaborou um projeto que nos estimulou a desenvolver os recursos metodológicos a cada orientação, correção e feedbacks. Tínhamos medo em pegar falta e ficamos sem saber como seria a avaliação agora neste cenário. Enfim, a professora nos recordou que no início da disciplina de projetos deixou claro sobre o processo de avaliação, que não seria o produto, mas, sim o processo! Este fator nos motivou a participar de todas as aulas $e$ orientações. Tenho que reconhecer que as aulas presenciais são muto eficazes, mas também tem que haver a compreensão, pois, o mundo está vivendo este problema. Posso dizer que a disciplina ocorreu de forma tranquila, a professora soube conduzir com humanismo, respeito e incentivo. Finalmente após cada etapa, finalizamos, discutimos o tema, as ideias e em seguida elaboramos coletivamente a apresentação. Um dos membros do grupo ficou responsável pela postagem final no sistema faculdade, após a flexibilização de datas com sucesso.

Discente - relator 4: os grupos conseguiram contribuir cada um com sua habilidade, dividimos as partes e juntávamos para ver o produto final, discutíamos coletivamente e com a professora, ou seja, cada um assumiu seu compromisso. No cenário de Covid- 19 precisávamos manter a seriedade para finalizar com sucesso. Todos os trabalhos foram apresentados a todos os grupos, assim tivemos a oportunidade de assistir de forma remota as apresentações, para assim ampliarmos o nosso projeto buscando contribuir para com nossos colegas $e$ consequentemente a comunidade redencense. Enfim, sabemos que teremos que enfrentar algumas dificuldades futuras em relação a várias questões, com principalmente financeiras e emocionais. Esperamos que as faculdades se preparem cada vez mais e se adaptem para esta nova realidade onde temos um ou outro colega que não tem acesso total à internet.

Fonte: Camilo (2020).

Em síntese, o docente planejou cada passo do projeto onde podemos perceber as etapas denominadas fase I e II em relação às metodologias ativas. "O papel do professor não mais como provedor e controlador direto das informações e da aprendizagem, mas como planejador e gestor das estratégias adequadas e mediador entre todos os recursos disponíveis...” (PETEROSSI; ITOCAZU, 2005, p. 106), agora o professor é agente mediador, que atua no processo facilitador de ensino aprendizagem.

No segundo momento, o docente - relator I demonstra que as ferramentas tecnológicas desempenharam um excelente apoio, porém demonstram claramente que também foi desafiante o processo de adaptação repentina. Segundo Weber \& Behrens (2010, p. 236),

A tecnologia aparece cada vez mais desenvolvida em todos os setores da sociedade, e não poderia deixar de estar presente também nas salas de aula, em práticas inovadoras. Computadores, televisão, pen-drives, projetores, ensino a distância e outros recursos surgem para apoiar os conteúdos e elevar o nível de possibilidades.

Em detrimento dos desafios e do advento de novas ferramentas educacionais, o professor de ensino superior atualmente desenvolve seu trabalho com o auxílio das TICs. É importante destacar que a formação continuada deste profissional para torná-lo cada vez mais apto a exercer 
sua função é de grande relevância - conhecer e manusear a tecnologia aliadas a métodos novos o tornará mais seguro como docente.

O docente - relator 2 afirma que incorporar os recursos tecnológicos para propiciar a interação e comunicação entre os sujeitos envolvidos é crucial para o ensino aprendizagem, conforme Molin (2010, p. 33):

Isto porque, a partir de 1960 e 1970 as TICs vêm exercendo poderosa influência em nossa cultura, nos levando a passar por sucessivas transformações de natureza científica, tecnológica, política, econômica e cultural. Obrigam os trabalhadores, em especial, os docentes, a se defrontarem com constantes desafios.

Entende-se que para inserir as novas formas de ensinar e aprender no ensino superior, é necessário aprender a aprender para transmitir, o professor deve conhecer para fazer. Sobre a impressão do discente - relator 3, percebe-se que para todos os envolvidos no processo educacional neste momento de mudanças psicossociais, as mudanças acarretaram uma certa insegurança e instabilidade, pois, a exigência educacional se tornou maior devido o objeto central do processo ser o aluno.

Todas as inovações são ótimas para os profissionais atentos às novidades, que estão sempre abertos a atualizar-se e a comunicar-se. Mas elas serão um tormento para pessoas acomodadas, que se acostumaram a fazer suas atividades sempre do mesmo jeito, como os professores que falam o tempo todo em aula e que impõem um único ritmo de aprendizagem (PIVA, 2013, p. o7).

O processo de inclusão, adaptação e uso da tecnologia deve ser mediado pelo docente envolvido 100\%. No decorrer do período de estudos fica ainda mais claro que a condução docente fará toda a diferença, ao trabalhar o ensino, indução e motivação para o estudo significativo.

A escola é um espaço privilegiado de interação social, mas este deve interligar-se e integrar-se aos demais espaços de conhecimento hoje existentes e incorporar os recursos tecnológicos e a comunicação via redes, permitindo fazer as pontes entre os conhecimentos se tornando um novo elemento de cooperação e transformação. (MERCADO, 1998, p. o2).

A escola deve oportunizar aos discentes, maior efetividade partindo do uso de métodos ativos e das TICs, garantindo assim a melhor qualidade de ensino, facilitando assim melhor relação em diversas áreas de conhecimentos.

$\mathrm{Na}$ visão do discente - relator 4 afirma que, as ferramentas utilizadas foram de grande apoio; afirma que a turma teve grandes dificuldades, mas enfrentaram com persistência a disciplina do semestre, as aulas síncronas, método voltado ao ensino aprendizagem que se 
assemelha ao ensino a distância. No entanto se desenvolvem de forma sistemática com aulas em tempo real com o professor e horário marcado. Ministrar disciplinas por meio de aulas síncronas é um grande desafio, principalmente para aqueles que têm certa dificuldade para lidar com as tecnologias (FIGUEIREDO et al., 2020), porém a adaptação é necessária, pois, este método impulsiona o aluno a ser protagonista de seu aprendizado para que haja a interação nas ações pedagógicas; e o docente com o papel de mediador, com o papel de mentor do planejamento das atividades a serem executadas (onde é relevante a atuação discente e docente no processo de ensino aprendizagem).

Conforme Libânio (1998), a formação continuada conduz os docentes a refletirem, pois, após executarem seus planos, lhes é concedida a oportunidade de repensar as ações e superar as dificuldades e, assim, replanejar para a próxima etapa. Assim, a expressão profissionalização docente e envolvimento do aprendiz são extremamente importantes para a aquisição da autonomia docente e discente em cenários como o atual (PANDEMIA, 2020), onde os resultados de cada processo sejam considerados eficazes e de qualidade.

\section{Metodologia}

Inicialmente foi desenvolvida a pesquisa bibliográfica seletiva, para um melhor conhecimento do assunto; e em seguida a formulação da problemática, da justificativa e dos objetivos; e por último a delimitação detalhada da pesquisa. E, para uma compreensão dos conteúdos foram desenvolvidos o referencial teórico e a redação final para melhor compreensão sobre o tema. Por se tratar de um relato de experiencia, foi realizada aplicação de questionário via Google Forms para a coleta dos depoimentos de professores e alunos de uma IES em Redenção-PA. Estes, por razões éticas, foram nomeados docente - relator $\mathrm{I}$, docente - relator 2 e discente I e discente 2, ambos nomeados como relatores.

A pesquisa buscou analisar e refletir sobre a aplicabilidade de tecnologias e metodologias ativas no ensino remoto devido à situação de pandemia, visto que docentes do país tiveram que passar pelo processo de adequação às novas formas de ensinar e os alunos de aprender, podemos caracterizar este fator como a problemática da pesquisa, pois, esta mudança trouxe vários desafios, como a dificuldade de acesso e adequação aos ambientes virtuais e a adaptação de professores que tinham seus planejamentos voltados para o contexto do ensino presencial, tipos de metodologias utilizadas e dos pontos fracos e/ou fortes identificados, com respaldo significativo em autores já consolidados no que tange os temas tratados. 


\section{Considerações Finais}

Esta pesquisa traz a reflexão acerca da visão docente e discente sobre a experiência do uso das tecnologias da informação e ferramentas no ensino considerado "remoto"; analisa a experiência sobre o uso das metodologias e tecnologias no ensino superior na execução de atividades virtuais como apoio à aprendizagem em período de pandemia do COVID-19 no município de Redenção (PA).

Aprendizagem Baseada em Projetos foi a metodologia utilizada para execução do plano anteriormente apresentado e para validar os relatos docentes e discentes; elaboração e execução de projetos são eficazes nas aulas presenciais ou virtuais, propiciando o desenvolvimento da aprendizagem significativa.

É perceptível a ansiedade discente e docente pela melhoria de sua preparação para o uso de novos meios de ensino. Agora é relevante priorizar o planejamento docente gestor para melhorias de estratégias didáticas pedagógicas, uma vez que o aluno mediado, orientado produz sua aprendizagem com todos os recursos oferecidos.

Durante a ação do projeto e sua execução, fica claro que o professor é de suma importância no processo educacional e que os alunos, as turmas, a faculdade devem estar preparadas para lidarem com as mudanças na metodologia de ensino. O professor precisa estar munido de motivação e conhecimentos sobre as metodologias ativas e incorporar novos métodos e ferramentas tecnológicas no cotidiano de aprendizagem discente para que haja segurança e confiabilidade na ação recíproca do conhecimento.

Os relatos dos sujeitos pesquisados demonstram ainda que o uso das TICs e metodologias ativas por si só não surtirão efeitos para a aquisição de habilidades e competências. A educação não vai estagnar, os desafios são diversos, adapta-se aulas presenciais em on-line. Por esta razão os estudos sobre os tipos de metodologias requerem maior atenção, pois, todos devem estar abertos às adaptações e novos modelos de ensino.

Por fim, conclui-se que a presente pesquisa não finda por aqui, esclarece que os profissionais docentes são definitivamente os transmissores de conhecimento e discentes os tomadores. Sendo assim, é necessário todo um aparato para que os resultados sejam alcançados, tais como, suportes tecnológicos, infraestrutura que atenda às reais necessidades atuais e formação continuada.

Considerando a finalização do trabalho, pode-se perceber a importância da inovação da educação, dos novos métodos e das tecnologias como suporte essencial neste período de Pandemia e principalmente em todos os momentos educacionais. As escolas e profissionais da educação devem 
se reinventar e constituir métodos diferenciados que venham fazer a diferença na vida dos educandos; e o docente deve investir na formação para a aprendizagem sobre os meios inovadores para o ensino daqui em diante, porque entende-se que nada será como antes.

\section{Referências}

BACICH, L.; NETO, A.; TREVISANI, F. M. (Org.). Ensino híbrido: personalização e tecnologia na educação. Porto Alegre: Penso, 2015.

BARBOSA, E. F.; MOURA, D. G. Metodologias ativas de aprendizagem na Educação Profissional e Tecnológica. B. Tec. Senac, v. 39, n. 2, p. 48-67, 2013.

BAUMAN, Z. Modernidade líquida. Tradução de Plínio Dentzien. Rio de Janeiro: Zahar, 2003.

BERBEL, N. As metodologias ativas e a promoção da autonomia dos estudantes. Seminário: Ciências Sociais e Humanas, Londrina, v. 32, n. I, p. 25-40, jan./jun. 201 I.

BERGMANN, J. Sala de aula invertida: uma metodologia ativa de Aprendizagem. Rio de Janeiro: Livros Técnicos e Científicos Editora Ltda., 2016.

BESSANT, J.; TIDD, J. Inovação e Empreendedorismo. Porto Alegre: Bookman, 2009.

BLIKSTEIN, P. O mito do mau aluno e porque o Brasil pode ser o líder mundial de uma revolução educacional. ABMES, 2010. Disponível em: www.abmes.com.br. Acesso em: 09 jul. 2020.

BRASIL. Decreto no 9.235, de is de dezembro de 2017. Dispõe sobre o exercício das funções de regulação, supervisão e avaliação das instituições de educação superior - IES e dos cursos superiores de graduação e de pós-graduação lato sensu, nas modalidades presencial e a distância, no sistema federal de ensino. Diário Oficial da União, i8 dez. 2017. Disponível: www.in.gov.br/en/web/dou/-/decreto-n-9-235-de-15-de-dezembro-de-2017-IIoI286-IIoI286.Acesso em: 04 ago. 2020.

. Portaria no 343 de 17 de março de 2020a. Dispõe sobre a substituição das aulas presenciais por aulas em meios digitais enquanto durar a situação de pandemia do Novo Coronavírus - COVID19. Diário Oficial da União, 18 mar. 2020. Disponível em: www.in.gov.br/en/web/dou/-/portarian-343-de-17-de-marco-de-2020-248564376. Acesso em: 03 ago. 2020.

. Portaria 345 de 19 de março de 2020b. Altera a Portaria MEC no 343, de 17 de março de 2020. Diário Oficial da União, 19 mar. 2020. Disponível em: www.in.gov.br/en/web/dou/-/portaria-n345-de-19-de-marco-de-2020-248881422. Acesso em: 04 ago. 2020.

. Portaria 395, de 15 de abril de 2020c. Prorroga o prazo previsto no § Iㅇ do art. I을 da Portaria no 343 , de 17 de março de 2020. Io vem prorrogar, por mais trinta dias, o prazo previsto no § I $\mathrm{o}$ do art. $\mathrm{I}$ o da Portaria no 343, de 17 de março de 2020. Diário Oficial da União, is abr. 2020. Disponível em: https://pesquisa.in.gov.br/imprensa/jsp/visualiza/index.jsp?data $=16 / 04 / 2020 \&$ jornal=515\&pagina $=6 \mathrm{I}$. Acesso em: 04 ago. 2020 . 
. Portaria 544, de 16 de junho de 2020d. Dispõe sobre a substituição das aulas presenciais por aulas em meios digitais, enquanto durar a situação de pandemia do novo Coronavírus - Covid-19, e revoga as Portarias MEC no 343, de 17 de março de 2020, no 345, de 19 de março de 2020, e no 473, de I2 de maio de 2020. Disponível em: www.in.gov.br/en/web/dou/-/portaria-n-544-de-16-de-junhode-2020-261924872. Acesso em: 04 ago. 2020.

BRITO, G. da S. Educação e novas tecnologias: um (re)pensar. Curitiba: Editora Intersaberes, 2012.

DEWEY, J. Vida e educação. ı. ed. São Paulo: Melhoramentos, 1978.

KENSKI, V. Educação e tecnologias. O novo ritmo da informação. Campinas: Papirus Editora, 2013.

KOCHHANN, L. E. Pós-pandemia: especialistas projetam ensino superior do futuro. Desafios da Educação, 2020. Disponível em: https://desafiosdaeducacao.grupoa.com.br/ensino-superiorfuturo-coronavirus/. Acesso em: 04 jul. 2020.

LIBÂNEO, J. C. Adeus Professor, Adeus Professora? Novas exigências educacionais e profissões docente. São Paulo: Cortez, 1998.

MARKHAM, T.; LARMER, J.; RAVITZ, J. Aprendizagem baseada em projetos: guia para professores de ensino fundamental e médio. Porto Alegre: Artmed, 2008.

MERCADO, L. P. L. Formação docente e novas tecnologias. In: CONGRESSO RIBIE, 4., I998. 378 Brasília. Anais... Brasília, 1998.

MOLIN, S. I. L. Novas Tecnologias na educação: transformações da prática pedagógica no discurso do professor. 2010. Dissertação (Mestrado). Universidade do Vale de Itajaí, Itajaí, 2010.

MORAN, J. M. Mudando a educação com metodologias ativas. In: SOUZA, C. A. de; MORALES, O. E. T. (Org.). Convergências midiáticas, educação e cidadania: aproximações jovens. Ponta Grossa: UEPG/PROEX, 2015. p. 15-33. (Coleção Mídias Contemporâneas, v. 2). Disponível em: www2.eca.usp.br/moran/wp-content/uploads/2013/r2/mudando_moran.pdf. Acesso em: 08 jul. 2020.

PETEROSSI, H. G.; ITOCAZU, N. A. As novas tecnologias de informação e comunicação e a prática docente. In:

Paulo: Pioneira, 2005. p. I13-130.

PIVA JUNIOR, D. Sala de aula digital: uma introdução à cultura digital para educadores. São Paulo: Saraiva, 2013.

ROCHA, F. Correntes pedagógicas contemporâneas. 2. ed. Aveiro: Estante, 1988.

WEBER, M. A. L.; BEHRENS. Paradigmas educacionais e o ensino com a utilização de mídias. Revista Intersaberes, Curitiba, a. 5, n. Io, p. 245-270, jul/dez. 2010. 